\title{
어깨위신경의 초음파 소견: 신경 전도 검사를 위한 최적의 위치
}

최준호, 정영하, 정유형, 양승남, 윤준식

고려대학교 구로병원 재활의학과

\section{Ultrasonographic Findings for the Suprascapular Nerve: Identifying the Optimal Site for Nerve Conduction Study}

\author{
Jun Ho Choi, Young Ha Jeong, Ju Hyong Jeoung, Seung Nam Yang, Joon Shik Yoon \\ Department of Physical Medicine and Rehabilitation, Korea University Guro Hospital, Seoul, Korea
}

\begin{abstract}
Objective: It is difficult to obtain reliable electrodiagnostic results by stimulating the suprascapular nerve (SSN) at Erb's point. We used ultrasound to determine the best location to evoke compound muscle action potentials (CMAPs) during electrical stimulation of the SSN.

Method: We observed the anatomic location of the SSN using ultrasonography (USG) and its relationship to the surrounding structures. Also, we compared the electrodiagnostic results for the SSN between the conventional nerve conduction study (NCS) technique and USG-guided NCS.

Results: The CMAP amplitude of the SSN in the USG-guided technique was significantly larger than that in the conventional technique $(p<0.05)$. The intensity of current stimulation was also significantly lower in the USG-guided technique than in the conventional technique $(p<0.05)$. The optimal site for electrical stimulation was a point $7.5 \mathrm{~cm}$ lateral from the sternal end (a point $43.0 \%$ of the total length of the clavicle from the sternal head of the clavicle) and $2.28 \mathrm{~cm}$ above and perpendicular to that point.

Conclusion: This study identified the location of the SSN in the supraclavicular region and provides an optimal site for stimulation of the SSN. USG-guided NCS could help to reduce patient discomfort and increase test accuracy.
\end{abstract}

Key Words: nerve conduction study, suprascapular nerve, ultrasound

\section{Introduction}

The suprascapular nerve (SSN) arises from the upper

Received April 9, 2019

Revised (1st) July 10, 2019, (2nd) July 20, 2019

Accepted July 29, 2019

Corresponding Author: Seung Nam Yang

Department of Physical Medicine and Rehabilitation, Korea University Guro

Hospital, 148 Gurodong-ro, Guro-gu, Seoul 08308, Korea

Tel: 82-2-2626-1500, Fax: 82-2-2626-1513, E-mail: snamyang@korea.ac.kr trunk of the brachial plexus, or its posterior division, with contributions from the $\mathrm{C} 5, \mathrm{C} 6$, and occasionally the $\mathrm{C} 4$ nerve roots. ${ }^{1}$ It supplies motor branches to the supraspinatus and infraspinatus muscles and is also believed to provide sensory innervation to the coracohumeral ligament, the coracoclavicular ligament, the subacromial bursa, and the posterior shoulder capsule. ${ }^{2.3}$ There are a number of mechanisms that can be responsible for injury to the SSN. These can include 
traction injury, repetitive activities, or compression of the nerve from a space-occupying lesion including ganglion cysts or rotator cuff tears. In addition, ossification of the transverse scapular ligament or spinoglenoid notch, or Parsonage-Turner syndrome could also result in suprascapular neuropathic symptoms. ${ }^{4-11}$

The gold standard for diagnosis of SSN injury is the electrodiagnostic test, including needle electromyography (EMG) and the nerve conduction study (NCS). ${ }^{12-16}$ Although several published studies have reported normative values, the variability of compound muscle action potentials (CMAP) exists for the SSN, and the criteria for interpretation can vary between different centers or practitioners. ${ }^{12,15}$ Technical errors or operator dependency also are issues with these tests, and therefore, lower test reliability. One of the reasons for such technical errors is that the electrical stimulation point for the SSN is quite ambiguous. ${ }^{12,15}$ Erb's point, or a point above the clavicle where the brachial plexus is located, is visually unclear and can be difficult to identify because it depends largely on various factors including the subject's body weight or neck posture. Increasing the stimulation intensity at Erb's point may induce volume conduction in other nerves, leading to misdiagnosis. Moreover, repetitive electrical stimulations or high intensity currents during electrical stimulation at Erb's point could result in patient discomfort.

Ultrasonography (USG) has been reported to be a useful imaging method for the assessment of many disorders affecting nerves. ${ }^{17-20}$ USG could be a useful method for the precise localization of the SSN. ${ }^{21-24}$ The purpose of this study was to determine the best SSN location for evoked CMAPs during nerve conduction tests using ultrasound. We hypothesized that the results obtained from the USG-guided NCS could give more accurate information for the SSN and alleviate the discomfort caused to patients by conventional NCS. Not only will these results provide the most appropriate location for SSN stimulation, but are also ex- pected to broaden our knowledge of SSN sonographic findings.

\section{Materials and Methods}

\section{1) Subjects}

Twenty healthy volunteers over 19 years old were recruited. Exclusion criteria included a history of cervical radiculopathy, any disease which results in peripheral polyneuropathy (e.g., diabetes, chronic alcohol use), any trauma around the neck and shoulder, or family history of hereditary neuropathy. Healthy volunteers were included from the community via local advertisement, and all subjects signed written informed consent. This study was approved by the Institutional Review Board of Korea University Guro Hospital.

\section{2) Conventional NCS}

Conventional NCS was performed according to the study of Lee et al. ${ }^{23}$ The stimulation point of the SSN is a point 2 or $3 \mathrm{~cm}$ above the clavicle and beyond the posterior border of the sternocleidomastoid at the level of the transverse process of the sixth cervical vertebra. The subject's neck was rotated to the opposite side of stimulation. The surface E1 electrode was placed several centimeters lateral to the medial border of the scapula and 2 to $3 \mathrm{~cm}$ below the scapular spine. The E2 surface electrode was positioned $2 \mathrm{~cm}$ more distal to the stimulating cathode. The examiner obtained the CMAP of the SSN with supramaximal stimulation. Then the examiner found the minimal intensity of current required to elicit maximal SSN CMAP. The NCS was performed using the VikingQuest electrodiagnostic system (Nicolet Biomedical, Madison, WI, USA). Skin temperature was maintained above $32^{\circ} \mathrm{C}$. Recordings were obtained with the following equipment settings: sensitivity, $5 \mathrm{mV}$ per division; sweep speed, 1 ms per division; and bandwidth 20 to $3,000 \mathrm{~Hz}$. 


\section{3) Ultrasound examination}

Ultrasound was performed using the HD 15 Ultrasound System (Philips, Bothell, WA, USA). Each subject was lying in the supine position. The neck was fully rotated toward the contralateral side. The C5 and C6 nerve roots were identified in the axial plane and when continued downward, we found that these two roots formed the upper trunk of the brachial plexus. We found the site where the SSN was best observed lateral to the upper trunk (Fig. 1). After the crosssectional area (CSA) of the SSN was confirmed at that location, we then marked the position on the skin surface. We measured the vertical distance and the horizontal distance to describe the relationship between the clavicle and the SSN (Fig. 2). The vertical distance was measured as the shortest distance from the marked point to the clavicle in the surface anatomy. The horizontal distance was measured from the sternal end of the clavicle to the vertical end, which is the intersection of the clavicle and the perpendicular line from the marked point to the clavicle. The horizontal distance ratio was also calculated as the relative ratio of the horizontal distance to the total length of the clavicle. The total length of the clavicle was measured from the sternal end to the acromial end. The

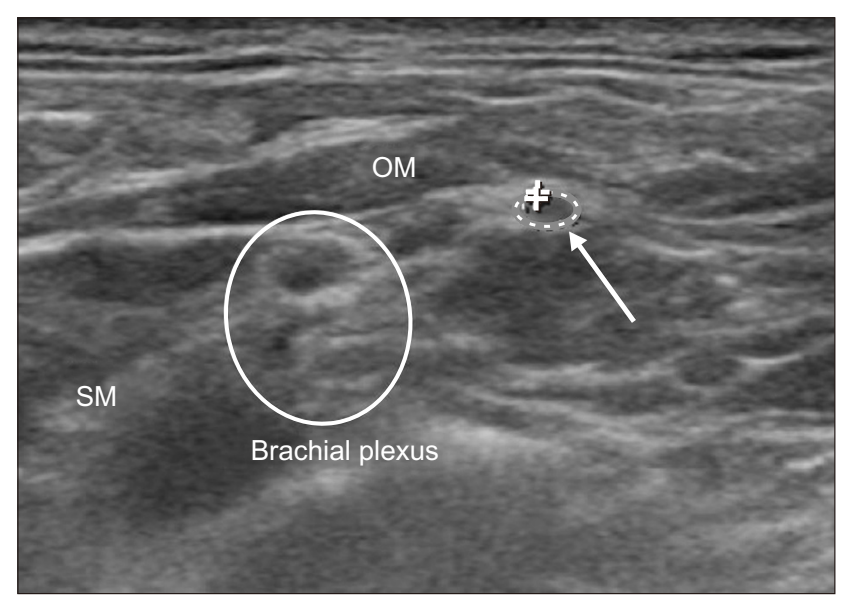

Fig. 1. The important landmarks for confirmation of the suprascapular nerve using ultrasonography are the omohyoid muscle (OM) and the scalene muscle (SM). The arrow marks the suprascapular nerve in the fascia layer under the $\mathrm{OM}$ in close relation to the brachial plexus indicated by the round circle. skin depth was measured from the skin to the SSN.

\section{4) Ultrasound-guided NCS}

The USG-guided NCS was stimulated using the cathode placed at the marked position found by the USG. The E1 and E2 electrodes were placed at the same locations as for conventional NCS. In our study, the examiner obtained the SSN CMAP with supramaximal stimulation. Then the examiner found the minimal intensity of current required to elicit maximal SSN CMAP.

\section{5) Statistical analysis}

Data were analyzed using SPSS 20.0 for Windows (IBM SPSS Inc., Armonk, NY, USA). The mean values and standard deviation of the measurements were calculated. To compare CMAP amplitude and current intensity at the stimulation between the conventional and USG-guided techniques, a paired t-test was performed. Results were considered statistically significant if the $\mathrm{p}$ value was $<0.05$.

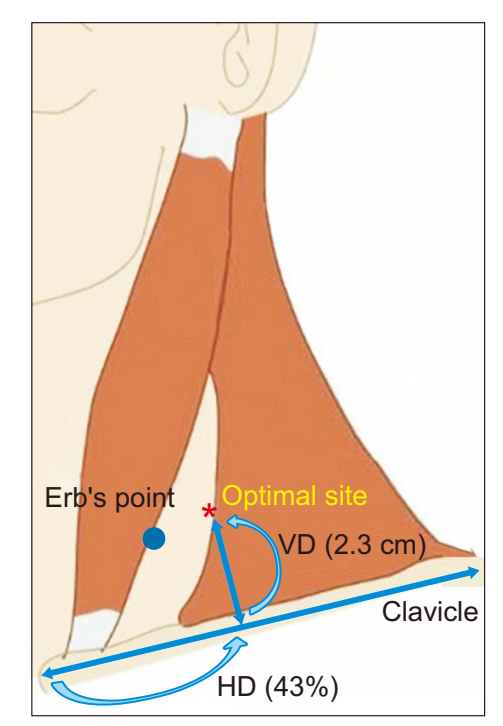

Fig. 2. The vertical distance (VD) was measured as the shortest distance from the marked point $\left(^{*}\right)$ to the clavicle in the surface anatomy. The horizontal distance (HD) was measured from the sternal end of the clavicle to the vertical end. The total length of the clavicle was measured from the sternal end to the acromial end. 


\section{Results}

Demographics of 20 healthy volunteers are as follows. The mean age and BMI were $31.6 \pm 8.78$ years and $22.87 \pm 2.17 \mathrm{~kg} / \mathrm{m}^{2}$, respectively $(\mathrm{n}=20)$. The male to female ratio was 2.33 .

Table 1 shows the SSN electrodiagnostic results using the two techniques. The mean values for CMAP amplitude using the conventional technique and the USG-guided technique were $5.47 \pm 0.92 \mathrm{mV}$ and 5.95 $\pm 1.09 \mathrm{mV}$. The CMAP amplitude of the SSN in the USG-guided technique was significantly larger than that of the conventional technique $(p<0.05)$. The mean value of the minimum intensity for maximal CMAP in the conventional NCS and USG guided NCS was $62.30 \pm 11.10 \mathrm{~mA}$ and $50.46 \pm 9.83 \mathrm{~mA}$, respectively. The intensity of current stimulation was also significantly lower in the USG-guided technique than that of the conventional technique $(\mathrm{p}<0.05)$.

SSN was identified in all of the participants using USG. The mean value of SSN CSA was $2.43 \pm 0.59$ $\mathrm{mm}^{2}$. The SSN was located $7.5 \pm 0.73 \mathrm{~cm}$ from the sternal end to the acromial end, which was $43.0 \pm$ $3.35 \%$ of the horizontal ratio. The vertical distance from the clavicle was $2.28 \pm 0.50 \mathrm{~cm}$. The mean value of depth from skin was $6.79 \pm 1.89 \mathrm{~mm}$ (Table 2).

\section{Discussion}

We successfully demonstrated the anatomical location of the SSN in this study. The USG-guided technique, in which we performed electrical stimulation at the position localized using ultrasonography, evoked a statistically significantly larger SSN CMAP than the conventional technique. This indicates that the CMAP

Table 1. Nerve Conduction Data for the Suprascapular Nerve

\begin{tabular}{lcc}
\hline \hline Parameters $(\mathrm{n}=20)$ & Conventional NCS* & USG-guided NCS* \\
\hline Amplitude $(\mathrm{mV})$ & $5.47 \pm 0.9^{* *}$ & $5.95 \pm 1.09^{* *}$ \\
Intensity $(\mathrm{mA})$ & $62.30 \pm 11.10^{* *}$ & $50.46 \pm 9.83^{* *}$ \\
\hline
\end{tabular}

Values are mean \pm standard deviation.

${ }^{* *} \mathrm{p}<0.05$. obtained with the conventional nerve conduction technique may have resulted from insufficient stimulation. Therefore, we found it necessary to perform SSN nerve conduction at the position we have identified to obtain more accurate results.

NCS is a safe and non-invasive test in which side effects have not been reported, but the electrical stimulation during NCS causes severe discomfort for patients. In many cases, even though NCS is necessary, some patients refuse the test due to this discomfort. In this study, the mean values of the minimal current intensity for maximal SSN CMAP were significantly lower using the USG-guided NCS than the conventional NCS. This result supports that the USG-guided technique can be more easily applied to patients who cannot tolerate the discomfort of high intensity electrical stimulation.

The sonographic findings identified in the current study not only supported the findings identified in the previous studies, but also provided new findings on the SSN. Bilfeld et al. evaluated SSN accessibility using USG in 4 cadavers and 30 healthy volunteers. ${ }^{25}$ They reported that the SSN in the supraclavicular portion had been easier to identify than in the scapular portion, and a segment of the SSN between these two portions was not visible. The present study identified the SSNs located in the supraclavicular region in all 20 healthy volunteers and found that this area could be the recommended location for USG-guided SSN block. Siegenthaler et al. assessed the SSN using

Table 2. Ultrasonographic Data for the Suprascapular Nerve

\begin{tabular}{lr}
\hline \hline Parameters $(\mathrm{n}=20)$ & \multicolumn{1}{c}{ Value } \\
\hline CSA $\left(\mathrm{mm}^{2}\right)$ & $2.43 \pm 0.59$ \\
Clavicle $(\mathrm{cm})$ & $17.45 \pm 1.13$ \\
VD $(\mathrm{cm})$ & $2.28 \pm 0.50$ \\
HD $(\mathrm{cm})$ & $7.5 \pm 0.73$ \\
HD ratio $(\%)$ & $43.0 \pm 3.35$ \\
Skin depth $(\mathrm{mm})$ & $6.79 \pm 1.89$ \\
\hline
\end{tabular}

Values are mean \pm standard deviation.

Vertical distance (VD): the shortest distance from the marked point to the clavicle, Horizontal distance (HD): horizontal distance from the sternal head of the clavicle to the vertical end, HD ratio: ratio of horizontal distance to the total length of the clavicle 
USG. ${ }^{18}$ They performed USG on 60 healthy volunteers and found that evaluating the SSN using USG is better in the lateral cervical region than at the level of the scapula and that the omohyoid muscle is a reliable anatomical landmark. Battaglia et al. studied the relationship between the SSN and omohyoid muscle in 33 healthy volunteers. ${ }^{21}$ The omohyoid muscle and the SSN tend to course together as they travel distally. In our study, the SSN was also located near the omohyoid muscle. Based on the present study and many other studies, the omohyoid muscle is an important anatomic landmark for USG-guided SSN block. However, it is difficult to identify the omohyoid muscle via surface anatomy, which makes it difficult to utilize as a landmark during nerve conduction studies. We found the SSN stimulation site on the skin surface, 7.5 $\mathrm{cm}$ lateral to the sternal end of the clavicle and 2.28 $\mathrm{cm}$ vertical to the vertical end. The location information confirmed in this study can help clinicians deliver accurate stimulation to the SSN during nerve conduction studies. Laumonerie et al.'s study included 30 healthy volunteers and 5 cadavers. ${ }^{1}$ The diameter of the SSN at the level of its origin averaged $1.33 \mathrm{~mm}(1 \sim 9$ $\mathrm{mm})$. In the current study, SSN CSA was measured in the supraclavicular area. Considering that recent USG studies prefer CSA to the diameter of the nerve as a measurement of nerve sonographic findings, the CSA values for the SSNs confirmed in this study may be more useful for sonographic studies. Laumonerie et al. also measured the depth of the skin surface to the SSN, and the mean depth was $5.12 \mathrm{~mm}$ (2.7 10.6 $\mathrm{mm})$. Our findings suggest the mean depth is 6.79 $\mathrm{mm}$. The skin depth presented in the above findings was less than $1 \mathrm{~cm}$, so this should be kept in mind when using USG guided SSN blocks; the needle approach should be shallow.

This study is the first to suggest the usefulness of a USG-guided NCS technique for the SSN. Recently, USG guided NCS has been studied for various peripheral nerves. Boon et al. investigated the USG-guided lateral femoral cutaneous nerve (LFCN) NCS technique in a population of normal subjects, of whom $50 \%$ had a body mass index within the obese range $(>27.5) .{ }^{26}$ They found that responses were obtained in at least $92 \%$ of subjects using either of the techniques, and $92 \%$ of normal subjects had $<60 \%$ interside variability using the USG guided technique. Park et al. also studied the utility of a USG-guided LFCN NCS technique. ${ }^{27}$ In that study, the SNAP amplitude of the LFCN using the USG-guided technique was significantly larger than that of conventional NCS. Kim et al. studied the USG-guided NCS for the superficial peroneal nerve. ${ }^{28}$ They suggested the optimal recording position in the NCS for the superficial peroneal nerve was one-third medial to the lateral malleolus for the intermediate dorsal cutaneous nerve and just lateral to the midpoint of the intermalleolar line for the medial dorsal cutaneous nerve. Evangelopoulos et al. studied electrode positioning for the saphenous NCS using USG. ${ }^{29}$ They concluded that SNAP amplitudes of the recorded sensory nerve action potentials were higher with the ultrasound-guided needle electrode recordings than with surface recordings. The present study also confirmed that the USG-guided technique evoked better CMAP values than the conventional technique. We suggest using the USG guided technique if it is difficult to obtain accurate results using conventional NCS or to determine the stimulation location at the surface.

This study has some limitations. First of all, since the volunteers enrolled in this study included few obese individuals, a study including more obese people could reveal different results for the SSN nerve conduction or sonographic findings. Secondly, the number of subjects enrolled was relatively small. Therefore, future studies that include larger samples are recommended. In this study, we did not evaluate inter-observer reproducibility because one sonographer performed all sonographic examinations for the study. Lastly, we did not include a patient with SSN neuropathy. Thus, we cannot assure the utility of the USG-guided technique in patients with SSN neuropathy. Future evaluations should identify the utility of 
USG-guided stimulation by including patients with SSN neuropathy.

Our study contributes to identifying the location of the SSN in the supraclavicular region and provides an optimal site for SSN stimulation. This also could help relieve patient discomfort during such examinations. Further studies that include a large number of patients with SSN neuropathy are recommended to replicate and expand our findings.

\section{References}

1. Laumonerie P, LapĖgue F, Chantalat E, Sans N, Mansat P, Faruch: Description and ultrasound targeting of the origin of the suprascapular nerve. Clin Anat 2017: 30: 747-752

2. Bigliani LU, Dalsey RM, McCann PD, April EW, Surgery R: An anatomical study of the suprascapular nerve. Arthroscopy 1990: 6: 301-305

3. Aszmann OC, Dellon AL, Birely BT, McFarland: Innervation of the human shoulder joint and its implications for surgery. Clin Orthop Relat Res 1996: 330: 202-207

4. Albritton MJ, Graham RD, Richards II RS, BasamaniaCJ: An anatomic study of the effects on the suprascapular nerve due to retraction of the supraspinatus muscle after a rotator cuff tear. J Shoulder Elbow Surg 2003: 12: 497-500

5. Collin P, Treseder T, Lädermann A, Benkalfate T, Mourtada $\mathrm{R}$, Courage $\mathrm{O}$ et al.: Neuropathy of the suprascapular nerve and massive rotator cuff tears: a prospective electromyographic study. J Shoulder Elbow Surg 2014: 23: 28-34

6. FritZ RC, Helms CA, Steinbach LS, Genant HK: Suprascapular nerve entrapment: evaluation with MR imaging. Radiology 1992: 182: 437-444

7. Gaskin CM, Helms CA: Parsonage-Turner syndrome: MR imaging findings and clinical information of 27 patients. Radiology 2006: 240: 501-507

8. Lee BC, Yegappan M, Thiagarajan P: Suprascapular nerve neuropathy secondary to spinoglenoid notch ganglion cyst: case reports and review of literature. Ann Acad Med Singapore 2007: 36: 1032

9. Semmler A, von Falkenhausen M, Schröder R: Suprascapular nerve entrapment by a spinoglenoid cyst. Neurology 2008: 70: 890

10. Sharma RR, Pawar SJ, Netalkar AS: Schwannoma of the suprascapular nerve presenting with atypical neuralgia: case report and review of the literature. J Clin Neurosci 2001: 8:
60-63

11. Zehetgruber H, Noske H, Lang T, Wurnig C: Suprascapular nerve entrapment. A meta-analysis. Int Orthop 2002: 26: 339-343

12. Buschbacher RM, Weir SK, Bentley JG, Cottrell EJP: Normal motor nerve conduction studies using surface electrode recording from the supraspinatus, infraspinatus, deltoid, and biceps. PM R 2009: 1: 101-106

13. Gassel MM: A test of nerve conduction to muscles of the shoulder girdle as an aid in the diagnosis of proximal neurogenic and muscular disease. J Neurol Neurosurg Psychiatry 1964: $27: 200$

14. Horning MR, Kraft GH, Guy A: Latencies recorded by intramuscular needle electrodes in different portions of a muscle: variation and comparison with surface electrodes. Arch Phys Med Rehabil 1972: 53: 206-211

15. Kraft GH: Axillary, musculocutaneous and suprascapular nerve latency studies. Arch Phys Med Rehabil 1972: 53: 383-387

16. Liveson JA, Bronson MJ, Pollack MA: Suprascapular nerve lesions at the spinoglenoid notch: report of three cases and review of the literature. J Neurol Neurosurg Psychiatry 1991: 54: 241-243

17. Duncan I, Sullivan P, Lomas F: Sonography in the diagnosis of carpal tunnel syndrome. Am Roentgen Ray Soc 1999: 173: 681-684

18. Siegenthaler A, Moriggl B, Mlekusch S, Schliessbach J, Haug M, Curatolo $\mathrm{M}$ et al.: Ultrasound-guided suprascapular nerve block, description of a novel supraclavicular approach. Reg Anesth Pain Med 2012: 37: 325-328

19. Won SJ, Kim BJ, Park KS, Yoon JS, Choi H: Reference values for nerve ultrasonography in the upper extremity. Muscle Nerve 2013: 47: 864-871

20. Yang SN, Yoon JS, Kim SJ, Kang HJ, Kim SH: Movement of the ulnar nerve at the elbow: a sonographic study. J Ultrasound Med 2013: 32: 1747-1752

21. Battaglia PJ, Haun DW, Dooley K, Kettner NW: Sonographic measurement of the normal suprascapular nerve and omohyoid muscle. Man Ther 2014: 19: 165-168

22. Chan CW, Peng PW: Suprascapular nerve block: a narrative review. Reg Anesth Pain Med 2011: 36: 358-373

23. Lee HJ, DeLisa JA: Manual of nerve conduction study and surface anatomy for needle electromyography, 4th ed, Philadelphia: Lippincott Williams \& Wilkins, 2005, pp105106

24. Muhly WT, Orebaugh SL: Sonoanatomy of the vasculature at the supraclavicular and interscalene regions relevant for 
brachial plexus block. Acta Anaesthesiol Scand 2011: 55: 1247-1253

25. Bilfeld MF, Lapègue F, Sans N, Gandois HC, Laumonerie P, Larbi A: Ultrasonography study of the suprascapular nerve. Diagn Interv Imaging 2017: 98: 873-879

26. Boon AJ, Bailey PW, Smith J, Sorenson EJ, Harper CM, Hurdle MF: Utility of ultrasound-guided surface electrode placement in lateral femoral cutaneous nerve conduction studies. Muslce Nerve 2011: 44: 525-530
27. Park BJ, Joeng ES, Choi JK, Kang S, Yoon JS, Yang SN: Ultrasound-guided lateral femoral cutaneous nerve conduction study. Ann Rehabil Med 2015: 39: 47

28. Kim KH, Park BK, Kim DH, Kim Y: Sonography-guided recording for superficial peroneal sensory nerve conduction study. Muslce Nerve 2018: 57: 628-633

29. Evangelopoulos ME, Humpert S, Rösler KM: UltrasoundGuided Electrodes for Conduction Studies of the Saphenous Nerve. J Clin Neurophysiol 2017: 34: 243-247 